13,03

\title{
Состояние топологического изолятора в тонких пленках висмута под воздействием плоскостной деформации растяжения
}

\author{
() Е.В. Демидов, В.М. Грабов, В.А. Комаров, Н.С. Каблукова, А.Н. Крушельницкий \\ Российский государственный педагогический университет им. А.И. Герцена, \\ Санкт-Петербург, Россия \\ E-mail: demidov_evg@mail.ru
}

\begin{abstract}
Приведены результаты экспериментального исследования гальваномагнитных свойств тонких пленок висмута, находящихся под воздействием плоскостной деформации растяжения вследствие меньшего температурного коэффициента расширения материала подложки по сравнению с висмутом. Исследованы удельное сопротивление, магнетосопротивление и коэффициент Холла в интервале температур 5-300 K и магнитном поле до $0.65 \mathrm{~T}$. Рассчитаны концентрации носителей заряда. Обнаружено существенное возрастание концентрации носителей заряда для пленок толщиной меньше $30 \mathrm{~nm}$, что указывает на возможное увеличение роли поверхностных состояний и проявление свойств топологического изолятора в тонких пленках висмута на подложках из слюды.
\end{abstract}

Работа выполнена при финансовой поддержке Минобрнауки России в рамках государственного задания, проект № 3.4856.2017/8.9, и РФФИ, грант № 16-32-00313.

DOI: $10.21883 /$ FTT.2018.03.45543.07D

\section{1. Введение}

Новый класс материалов, топологические изоляторы на базе полупроводников с инвертированным спектром, широко исследуется в последнее время [1-5]. В топологических изоляторах сильное спин-орбитальное взаимодействие приводит к инверсии энергетического спектра и возникновению спин-расщепленных поверхностных состояний с дисперсией Дираковского типа [5], т.е. линейной зависимостью энергии от импульса $E=v_{F} p$, где $v_{F}-$ фермиевская скорость, $p-$ импульс носителей заряда. Вследствие сильного спин-орбитального взаимодействия носители заряда не чувствительны к рассеянию на дефектах, не нарушающему симметрию обращения времени, т.е. в этих состояниях они могут двигаться вдоль поверхности объемного материала почти без потери энергии. Таким образом, в данных материалах поверхностные состояния более устойчивы и обеспечивают высокую поверхностную проводимость.

В настоящее время большое количество веществ относят к топологическим изоляторам. Первым $3 D$-топологическим изолятором экспериментально идентифицирован твердый раствор висмут-сурьма с концентрацией сурьмы 9 at.\% [6]. Все известные топологические изоляторы, как и твердый раствор висмут-сурьма, представляют собой полупроводники с малой шириной запрещенной зоны. Основная проблема при исследовании транспортных свойств топологических изоляторов состоит в том, что „топологически защищенный“ слой, являясь очень тонким, шунтируется объемом образца. Поэтому транспортные эффекты, связанные с состоянием топологического изолятора, должны быть наиболее заметны в тонких пленках при низких температурах.

Чистые массивные монокристаллы висмута являются полуметаллами с концентрацией носителей заря- да $3 \cdot 10^{23} \mathrm{~m}^{-3}$ при $4.2 \mathrm{~K}$ и $4 \cdot 10^{23} \mathrm{~m}^{-3}$ при $77 \mathrm{~K}$ [7]. В работе [8] показано, что вследствие деформаций в системе пленка-подложка, обусловленных различием коэффициентов температурного расширения (КТР) материалов пленки и подложки, при низкой температуре происходит изменение положения актуальных экстремумов валентной зоны и зоны проводимости. В пленках висмута на подложках с КТР меньшим, чем у висмута, происходит изменение параметров кристаллической структуры аналогично тому, как это происходит при возрастании концентрации сурьмы в твердом растворе висмут-сурьма. В случае использования подложки из слюды (мусковит) при понижении температуры до $77 \mathrm{~K}$, вследствие деформаций в системе пленка-подложка происходит изменение параметров решетки висмута, аналогичное тому, которое происходит при добавлении примерно 5 at.\% $\mathrm{Sb}$ в $\mathrm{Bi}[8]$. Таким образом, в пленке Ві на подложке из слюды при низкой температуре возможен переход из полуметаллического в полупроводниковое состояние. Вследствие этого перехода возможно проявление в тонких пленках висмута состояния топологического изолятора, подобного наблюдаемому в твердом растворе висмут-сурьма в полупроводниковой области. Поверхностные состояния в первую очередь должны проявляться ростом концентрации носителей заряда при уменьшении толщины пленки.

Кристаллы слюды (мусковит), имеющие атомарно гладкую поверхность, позволяют получать пленки висмута с высокосовершенной кристаллической структурой [9].

В данной работе проведено исследование гальваномагнитных свойств тонких пленок висмута толщиной от 15 до $70 \mathrm{~nm}$ в интервале температур $(5-300 \mathrm{~K})$ и магнитного поля до 0.65 Т. Отдельные результаты приведены для пленок толщиной $100 \mathrm{~nm}, 150 \mathrm{~nm}$ и $300 \mathrm{~nm}$. 


\section{2. Методика эксперимента}

Напыление пленок производилось методом электронно-лучевого испарения мишени Ві чистотой $99.999 \%$ в вакууме при давлении остаточных газов не выше $2 \cdot 10^{-8}$ Torr с использованием безмасляной системы откачки. Температура подложки в процессе напыления пленки составляла $140^{\circ} \mathrm{C}$. Отжиг пленки проводился непосредственно в установке для напыления в вакууме при температуре $200^{\circ} \mathrm{C}$ в течение $60 \mathrm{~min}$. В качестве подложки использовалась слюда (мусковит).

Толщина пленок задавалась в процессе напыления кварцевым измерителем толщины. Для дополнительного контроля толщины тонких пленок висмута использовался метод на основе атомно-силовой микроскопии и избирательного химического травления, позволивший контролировать толщину пленки висмута, с погрешностью менее $10 \%$ [10]. В качестве химического травителя использовалась смесь концентрированных азотной и уксусной кислот в соотношении $1: 200$ (по объему).

Исследование электрических свойств проводилось по классической методике на постоянном токе в постоянном магнитном поле. Температура в процессе измерения стабилизировалась.

\section{3. Экспериментальные результаты и их обсуждение}

Исследование структуры полученных пленок висмута методами атомно-силовой микроскопии, рентгеноструктурного анализа и дифракции обратно рассеянных электронов показали, что все пленки имеют блочную структуру с ориентацией плоскости (111) Ві параллельно плоскости подложки. Соседние блоки имеют согласованную ориентацию, при которой оси $C_{3}$ и оси $C_{2}$ антипараллельны, а оси $C_{1}$ - параллельны. По картам кристаллографических ориентаций пленок был определен средний размер блоков. Для пленок толщиной менее $70 \mathrm{~nm}$ средний размер блоков составлял $\sim 0.75 \mu \mathrm{m}$, примерно на порядок превышал толщину пленок и слабо зависел от ее величины. В связи с этим при анализе полученных экспериментальных результатов по гальваномагнитным свойствам не учитывалось изменение влияния рассеяния носителей заряда на границах блоков на зависимости гальваномагнитных свойств от толщины пленки.

На рис. 1 приведена температурная зависимость удельного сопротивления $\rho$ пленок Ві различной толщины.

Пленки с толщинами $50-70 \mathrm{~nm}$ характеризуются монотонным возрастанием удельного сопротивления при понижении температуры и стремлением к насыщению в области температур ниже $15 \mathrm{~K}$. Уменьшение толщины пленок менее $33 \mathrm{~nm}$ приводит к появлению при низкой температуре области с температурным ходом удельного сопротивления, характерным для металлов. Образовавшийся максимум на температурной зависимости удель-

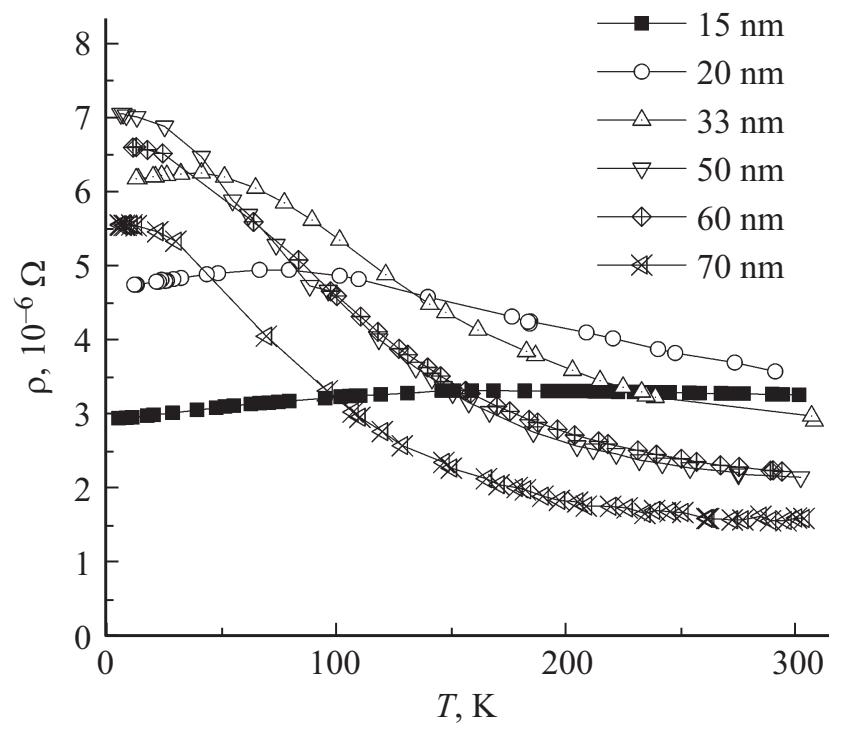

Рис. 1. Температурные зависимости удельного сопротивления пленок висмута различной толщины.

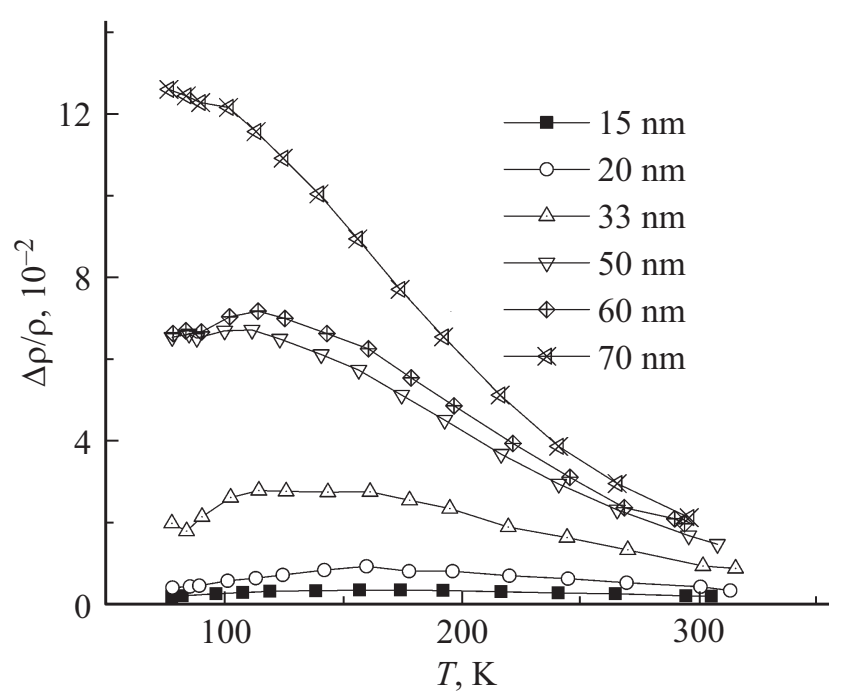

Рис. 2. Температурные зависимости относительного магнетосопротивления пленок висмута различной толщины. $B=0.65 \mathrm{~T}, B \| C_{3}$.

ного сопротивления сдвигается в область более высоких температур с уменьшением толщины пленок.

Результаты исследования зависимости относительного магнетосопротивления $(\Delta \rho / \rho)$ от температуры в слабом магнитном поле представлены на рис. 2. С уменьшением толщины пленки происходит уменьшение относительного магнетосопротивления. С понижением температуры от $300 \mathrm{~K}$ до $77 \mathrm{~K}$ в пленках толщиной более $33 \mathrm{~nm}$ происходит рост удельного сопротивления, однако для пленок толщиной от $33 \mathrm{~nm}$ и менее рост удельного сопротивления сменяется его уменьшением. Образовавшийся максимум смещается в область более высокой температуры с уменьшением толщины пленки. 


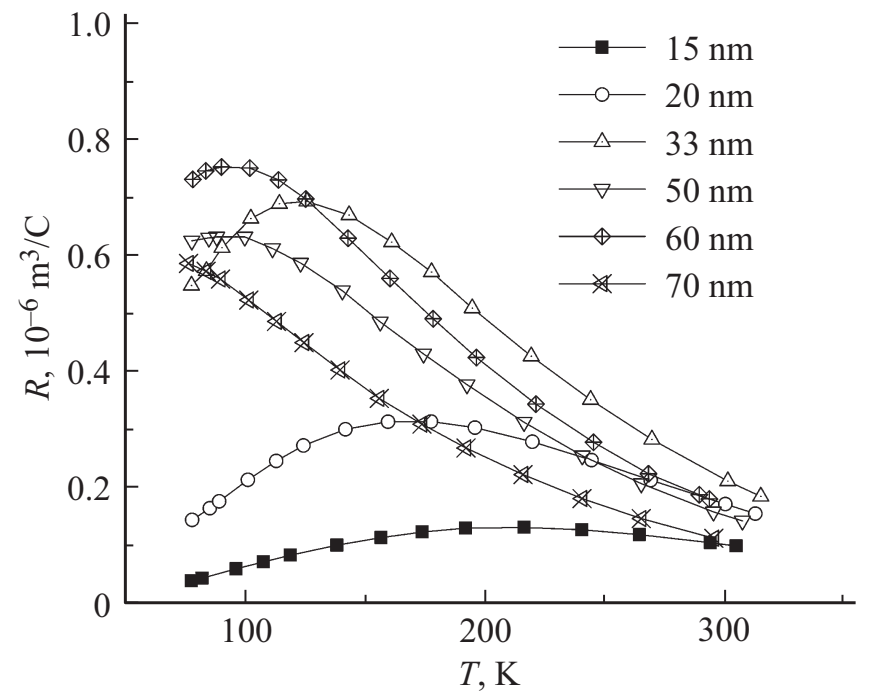

Рис. 3. Температурные зависимости коэффициента Холла пленок висмута различной толщины. $B=0.65 \mathrm{~T}, B \| C_{3}$.

Это означает, что с понижением температуры, начиная с некоторого ее значения, в пленках толщиной менее $33 \mathrm{~nm}$ подвижность носителей заряда уменьшается, а не остается постоянной, как в более толстых, что при условии уменьшения удельного сопротивления может быть обусловлено ростом концентрации носителей заряда при понижении температуры.

Рост проводимости с одновременным уменьшением магнетосопротивления при уменьшении толщины пленки указывает на рост концентрации носителей заряда при уменьшении толщины в исследуемых структурах.

Температурные зависимости коэффициента Холла исследуемых пленок в магнитном поле 0.65 T представлены на рис. 3.

Измерения показали, что коэффициент Холла всех полученных пленок положителен. На температурных зависимостях коэффициента Холла наблюдается максимум в области низкой температуры. При уменьшении толщины пленки максимум на зависимости коэффициента Холла смещается в область более высокой температуры и для пленки толщиной $15 \mathrm{~nm}$ она составляет $\sim 200 \mathrm{~K}$.

Для определения концентрации и подвижности носителей заряда были использованы уравнения для коэффициентов переноса в монокристаллах висмута в отсутствии магнитного поля и в слабом магнитном поле. С учетом кристаллографической ориентации пленочного кристалла висмута на подложке из слюды можно утверждать, что измеряемые на пленках висмута величины удельного сопротивления, магнетосопротивления в поперечном магнитном поле и коэффициента Холла соответствуют компонентам $\rho_{11}, \rho_{11,33}$, и $R_{12,3}$ монокристалла висмута для области слабого магнитного поля. С учетом вышеизложенного, для зонной структуры висмута в пренебрежении углом наклона электронных поверхностей Ферми измеряемые величины коэффици- ентов переноса можно выразить через концентрации и подвижности носителей заряда следующим образом [11]:

$$
\begin{gathered}
\sigma=\frac{1}{\rho}=\sigma_{11}=e n\left[\frac{1}{2}\left(u_{1}^{-}+u_{2}^{-}\right)+u^{+}\right], \\
R=R_{12,3}=\frac{e n}{\sigma_{11}^{2}}\left[B_{n} u_{1}^{-} u_{2}^{-}-B_{p}\left(u^{+}\right)^{2}\right], \\
\frac{\Delta \rho}{B^{2}}=\rho_{11,33}=-\rho_{11}^{2}\left[e n C_{p} U^{+3}\right. \\
\left.+\frac{1}{2} e_{n} C_{n} U_{1}^{-} U_{2}^{-}\left(U_{1}^{-}+U_{2}^{-}\right)\right]-\sigma_{11}\left(R_{12,3}\right)^{2},
\end{gathered}
$$

где $B_{n ; p}-$ Холл-факторы и $C_{n ; p}-$ факторы магнетосопротивления. Для квадратичного закона дисперсии и времени релаксации, не зависящего от энергии, эти факторы в первом приближении можно принять равными единице, что справедливо для висмута $[11], u^{+}, u_{1}^{-}, u_{2}^{-}-$ подвижности дырок и электронов относительно осей симметрии изоэнергетических поверхностей, лежащих в плоскости (111), e - элементарный заряд, $n-$ концентрация носителей заряда в пленке.

Для висмута, легированного теллуром, в том числе в тонкопленочном состоянии, было показано [7,12], что соотношение подвижностей электронов $u_{1}^{-}$и $u_{2}^{-}$можно принять постоянным, не зависящим от концентрации легирующей примеси и температуры, равным (4)

$$
u_{1}^{-}: u_{2}^{-} \approx 20 \text {. }
$$

На основе уравнений (1-3) и предположения справедливости соотношения (4) рассчитаны концентрации носителей заряда в исследованных пленках для температуры $77 \mathrm{~K}$. На рис. 4 представлена зависимость концентрации носителей заряда от толщины пленки висмута на слюде в интервале толщин $15-300 \mathrm{~nm}$.

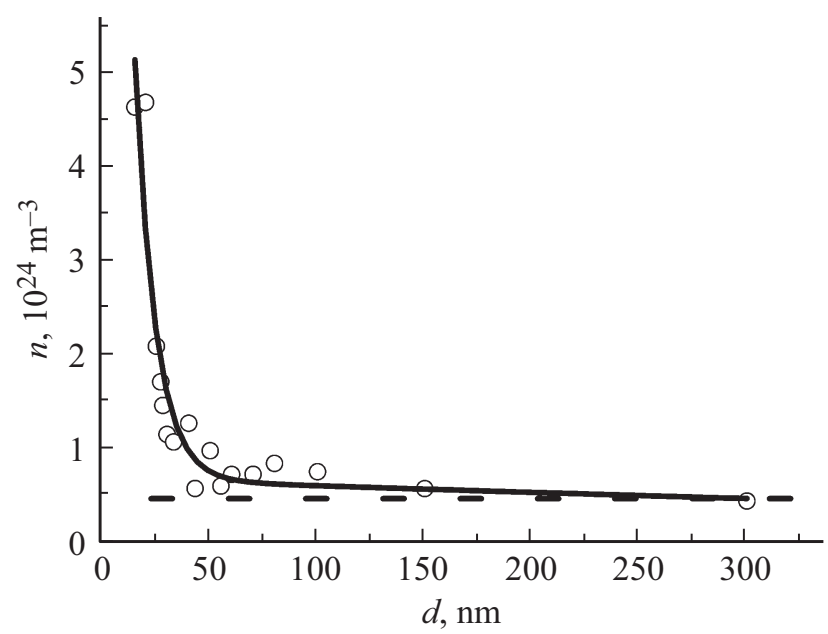

Рис. 4. Зависимость концентрации носителей заряда от толщины пленки висмута при температуре $77 \mathrm{~K}$. Пунктиром отмечено значение концентрации носителей заряда в массивном монокристалле висмута при температуре $77 \mathrm{~K}$. 
Как видно из представленных результатов расчета, значение концентрации носителей заряда в пленках толщиной 100-300 nm практически совпадает со значением концентрации в монокристалле висмута и существенно возрастает для пленок толщиной менее $30 \mathrm{~nm}$.

Выявленное существенное увеличение концентрации носителей заряда для пленок висмута толщиной менее $30 \mathrm{~nm}$, возможно, связано с увеличением роли поверхностных состояний с уменьшением толщины пленки и проявлением свойств топологического изолятора в тонких пленках висмута на подложках из слюды.

Следует, однако, отметить, что возможен и другой механизм увеличения концентрации носителей заряда. Этот механизм связан с изменением параметров кристаллической решетки Вi в наноразмерных объектах. В работе [13] отмечается, что при уменьшении размера кристаллита до 2-15 nm происходит уменьшение параметра $a$ гексагональной ячейки на $1.3 \%$ и одновременное увеличение $c / a$ на $2.5 \%$. Подобное искажение кристаллической решетки висмута, по характеру и по величине, происходит в пленках висмута на подложках с большим КТР (монокристалл $\mathrm{NaCl}$ ) при $77 \mathrm{~K}$. Эти пленки характеризуются при $77 \mathrm{~K}$ значительно большей (в 4 раза) концентрацией носителей заряда, чем монокристалл Вi [8]. Однако экспериментального подтверждения подобного изменения параметров решетки в пленках висмута на подложках из слюды при понижении температуры до $77 \mathrm{~K}$ пока не получено.

\section{4. Заключение}

Анализ полученных экспериментальных результатов показывает, что в пленках висмута толщиной более $50 \mathrm{~nm}$ значение концентрации носителей заряда близко к ее значениям в массивном монокристалле висмута, что соответствует неизменности энергетического спектра носителей заряда, а изменение гальваномагнитных коэффициентов обусловлено ограничением подвижности носителей заряда в результате рассеяния их при взаимодействии с поверхностью пленки. Выявленное существенное увеличение концентрации носителей заряда в пленках толщиной менее $30 \mathrm{~nm}$ может быть обусловлено как изменением параметров энергетического спектра носителей заряда, так и возможным увеличением роли поверхностных состояний и проявлением свойств топологического изолятора в тонких пленках висмута на подложках из слюды.

\section{Список литературы}

[1] L. Fu, C.L. Kane. Phys. Rev. B 76, 045302 (2007).

[2] M.Z. Hasan, C.L. Kane. Rev. Mod. Phys. 82, 3045 (2010).

[3] D.X. Qu, Y.S. Hor, J. Xiong, R.J. Cava, N.P. Ong. Science 329, 821 (2010).

[4] A. Taskin, Z. Ren, S. Sasaki, K. Segawa, Y. Ando. Phys. Rev. Lett. 107, 016801 (2011).
[5] T. Ryuji, M. Shuichi. Semicond. Sci. Technol. 27, 124005 (2012).

[6] D. Hsieh, D. Qian, L. Wray, Y. Xia, Y.S. Hor, R.J. Cava, M.Z. Hasan. Nature 452, 970 (2008).

[7] Г.А. Иванов, В.М. Грабов. ФТП 29, 1040 (1995).

[8] В.М. Грабов, В.А. Комаров, Н.С. Каблукова. ФТТ 58, 605 (2016).

[9] В.М. Грабов, Е.В. Демидов, В.А. Комаров. ФТТ 52, 1219 (2010).

[10] Е.В. Демидов, В.А. Комаров, А.Н. Крушельницкий, А.В. Суслов. ФТП 51, 877 (2017).

[11] R.H. Zitter. Phys. Rev. 127, 1471 (1962).

[12] В.М. Грабов, Е.В. Демидов, В.А. Комаров, Д.Ю. Матвеев, А.А. Николаева, Д. Маркушевс, Е.В. Константинов, Е.Е. Константинова. ФТП 48, 648 (2014).

[13] N.D. Lisgarten, S.J. Peppiatt, J.R. Samblest. J. Phys. C 7, 2263 (1974). 